\title{
3 Research Square

\section{The mediating effects of quality of life, depression, and generalized anxiety on perceived work barriers for people diagnosed with Neurofibromatosis Type \\ 1}

Frank D Buono ( $\square$ frank.buono@yale.edu )

Yale School of Medicine: Yale University School of Medicine https://orcid.org/0000-0003-1324-7857

Matthew E Sprong

Lock Haven University of Pennsylvania

Erina Paul

Merck: Merck \& Co Inc

Staci Martin

National Cancer Institute at Frederick: $\mathrm{NCl}$ at Frederick

Kaitlyn Larkin

Yale School of Medicine: Yale University School of Medicine

Amir Garakani

Yale School of Medicine: Yale University School of Medicine

\section{Research}

Keywords: Neurofibromatosis Type 1, Quality of Life, Mediation Analysis, Depression, Work Barriers

Posted Date: February 26th, 2021

DOl: https://doi.org/10.21203/rs.3.rs-256704/v1

License: (c) (i) This work is licensed under a Creative Commons Attribution 4.0 International License.

Read Full License 


\section{Abstract \\ Background}

Neurofibromatosis Type 1 (NF1) is a genetic disorder that presents with physical symptoms that can negatively impact numerous areas of one's life, including occupational and psychological functioning, with decreased quality of life compared to a normative population. The purpose of the current study was to explore the impact of psychological factors (anxiety and depression), along with quality of life and hope on employment barriers between those with NF1 and matched controls.

\section{Methods}

A total of 212 individuals were stratified into two groups (NF1 and matched controls) using a crosssectional design that collected a one-time response.

\section{Results}

A mediation analysis in which total barriers to employment success on the differences between groups with quality of life, anxiety and depression as the mediators, and levels of employment hope as the covariates were examined. The results did confirm a direct (.001) and indirect $(<.001)$ relationship between work barriers with NF1 to matched controls, and with quality of life, anxiety, and depression.

\section{Conclusions}

The current article demonstrates that quality of life can directly be affected by perceived barriers of employment within the NF1 population, while extending existing research by providing insight on the impact of quality of life on employment. Poorer mental health observed amongst people with a genetic disease can impact barriers of employment and quality of life.

\section{Introduction}

Neurofibromatosis Type 1 (NF1) is an autosomal dominant genetic disorder affecting an estimated 1 in 3000 individuals worldwide ${ }^{1}$. Typical presentations of NF1 can include plexiform neurofibroma tumors (PNs) (large tumors that grow from nerves and can distort the face, limbs, back, chest or abdomen), café au lait macules (dark pigmented spots on skin) ${ }^{2,3}$, and extensive dermal neurofibromas, which are tumors that present as bumps or lumps on the skin ${ }^{4}$. These highly visible and cosmetically disfiguring features of NF1 can leave individuals vulnerable to stigmatization and other social emotional difficulties such as depression, anxiety, and low self-esteem ${ }^{5}$. The direct appearance effects of NF1physical 
symptoms and the subsequent social emotional consequences can negatively impact numerous areas of one's life, including occupational functioning ${ }^{6,7}$.

In addition to increased stigmatization due to the aforementioned visible and cosmetically disfiguring symptoms, individuals with NF1 also cope with the unpredictable nature of the disease that varies in severity and medical complexity ${ }^{8}$. Consequently, those with NF1 are at increased risk for depression and anxiety ${ }^{9}$. A recent survey of 498 individuals with NF1 conducted by Cohen et al. ${ }^{5}$ found that $55 \%$ of all participants indicated a high likelihood for clinical depression. In addition, Pasini et al. ${ }^{10}$ reported findings revealing that children and young adults with NF1 had higher predisposition of developing an anxiety disorder. Suffering from the obstacles associated with a psychiatric disability, such as depression or anxiety, can have a direct negative impact on an individual's Quality of Life (QoL) ${ }^{6}$.

QoL is a multidimensional construct that represents the amalgamation of factors that affect a person's life including emotional, physical and social influences ${ }^{11,12}$. It has been documented that individuals with NF1 experience decreased QoL compared to the general population ${ }^{13}$. In addition, employment status has been shown to be a strong predictor of QoL, with employed individuals reporting greater QoL than those who are unemployed ${ }^{14,15}$. Previous research has shown that perceived QoL is negatively impacted when individuals do not have employment ${ }^{16}$. Likewise, research has shown that prolonged job insecurity (subjective perception or feelings of insecurity about the future of one's employment) has been negatively associated with psychological well-being ${ }^{17}$. Furthermore, Krueger et al. ${ }^{18}$ found that the longer an individual is unemployed, the higher the dissatisfaction and level of unhappiness with their lives (unhappiness rises the longer they are unemployed).

Although research has been conducted on QoL within NF1 populations regarding physical appearance, anxiety and depression ${ }^{19}$, little research has examined how disease-related barriers to successful employment impact the QoL of individuals with NF1. Through identifying and understanding the barriers to successful employment of individuals with NF1, steps can be taken to improve their QoL. The purpose of the current study was to explore the impact of psychological factors (anxiety and depression), along with QoL and employment hope on employment barriers between those with NF1 and matched controls. We hypothesized that individuals with NF1 would present with increased employment barrier scores compared with matched controls, thus suffering from reduced QoL and employment hope as opposed to individuals who were not diagnosed with NF1. Additionally, we hypothesize that individuals with NF1 will suffer increased generalized anxiety and depressive symptoms due to the perceived employment barriers compared with controls.

\section{Methods}

\section{Participants}

Two groups were recruited between March 2020 and August 2020: Individuals with NF1 and Matched Controls. The NF1 group consisted of 128 adults who were initially recruited through a mass email sent 
out to two of the largest NF advocacy listservs (NF Network and NF Northeast), after acquiring approval from both executive directors; 105 of these completed the assessments. Matched controls consisted of 115 individuals who were recruited via Qualtrics recruitment services, of which 108 successfully completed the assessments. The inclusion criterion for the study were as follows: 1 ) are at least 18 years old, 2) have a current documented case of NF1; 2a) no documented case of NF1 (matched controls). The exclusion criteria were the following: 1) unable to read or understand English at a 5th grade level, 2) no access to internet via computer, tablet, or smart phone, 3) diagnosis of NF2, and/or Schwannomatosis, 4) No current or prior chronic medical diseases (matched controls).

\section{Assessments}

The Generalized Anxiety Disorder Scale-7 (GAD-7) is a 7-item, self-rated scale developed in correspondence to the Diagnostic and Statistical Manual and updated for the 5th Edition (DSM-5), and is used as a screening tool and severity indicator for $G A D{ }^{20}$. Respondents are provided with seven different problems and indicate how bothered they were from each problem over the last 2 weeks. After reading each statement, one of four choices are provided and respondents can select one response ( $1=$ not at all, $2=$ several days, 3=over half days, 4=nearly every day). Each column is then added, and a total score is obtained, with scores falling into four levels of anxiety, including minimal (1-4), mild (5-9), moderate (10$14)$, and severe (15-21). Reliability of this assessment demonstrated a Cronbach's alpha of $0.92(a=$ $0.92)^{20}$.

The Patient Health Questionnaire (PHQ-9) is a nine-item, self-report scale that is used for screening, diagnosing, monitoring, and measuring the severity of depression [mild (scores of 5-9), moderate (scores of 10-14), moderately severe (scores of 15-19), severe (scores of 20-27)] ${ }^{21}$. Respondents are provided with nine different problems and indicate how bothered they were from each problem over the past 2 weeks by selecting one of four choices (1=not at all, 2=several days, 3=over half days, 4=nearly every day). Each column is then added, and a total score is obtained. Reliability of this assessment demonstrated a Cronbach's alpha of $0.89(a=0.89)^{21}$.

The Employment Hope Survey-Short (EHS-14) is a 14-item, self-report Likert scale based on the 24-item six-factor EHS. The Short-EHS maintains the 0 (strongly disagree)-10 (strongly agree) rating; however, it evaluates four factors (psychological empowerment, futuristic self-motivation, utilization of skills and resources, and goal orientation). Each factor is weighted and scored individually. Overall coefficient alpha and those for the factors of the Psychological Empowerment, Futuristic Self-Motivation, Utilization of Skills and Resources, and Goal Orientation subscales were $.932, .949, .833, .949$, and .931, respectively 22 .

The Barriers to Employment Success Inventory (BESI), Fifth Edition, is 50-item scale designed to assist an individual identifying and exploring the types of potential barriers that are keeping them from obtaining a good job, enjoying employment success, and advancing in their career ${ }^{23}$. Participants indicate their level of concern by selecting one of four choices ( $1=$ no concern, $4=$ greatest concern) that assess five barrier categories, including Personal and Financial, Emotional and Physical, Career Decision-Making and 
Planning, Job-Seeking Knowledge, and Education and Training. Total sub-scores ranging from 10-19 are low and indicate that an individual has recognized a few concerns or no concerns regarding the potential barriers in the specific section. Scores ranging from 20-30 are average and indicate that an individual has recognized several concerns regarding the potential barriers in each specific section. Scores ranging from 31-40 are high and indicate that the individual has recognized many concerns regarding the potential barriers to employment in each specific section. Sub-scores are cumulated and reported as an aggregate value. Reliability of the BESI sub-factors have demonstrated a Cronbach's alphas ranging between .87 and $.95^{23}$.

The Short-form Health Survey for the Medical Outcomes Study (SF-12) is a health-related quality of life scale that measures three dimensions both for functioning (physical, social and role) and for well-being (mental health, health perception and pain). It yields six numerical scores that are aggregated into a (0100) parameter, where a higher score indicates better functioning or well-being ${ }^{24}$.

\section{Procedure}

The current study was approved by the first author university's Human Subjects Committee and abides by the Helsinki Code of Ethics $(1975,2000)$. The current study was a cross-sectional design quantitative method that collected a one-time response from participants. Participants matched across both groups: gender (at minimum $45 \%$ were female), age, and no current major medical conditions (e.g., cancer, HIV/AIDS). All data collected from questionnaires were anonymized by the first author (FB) and stored in a secure online server hosted by the first author's institution.

Participants that agreed to participate in the study were instructed to click on the link at the bottom of the recruitment email. The link relocated the study participants to a password protected survey within Qualtrics. Prior to completing the assessments, potential participants were welcomed to the survey and requested to read and electronically sign (e-sign) the informed consent form that described the study, how the data would be used, and how it was recorded. Copies of the informed consents were securely emailed to the participant. Participants were stratified into two groups, based on answering research questions ("Do you have Neurofibromatosis?" and "If marked yes, what type of Neurofibromatosis do you have"): NF1 and Matched Controls. Once participants completed the assessments, a debriefing statement was provided. Four $\$ 50$ USD Amazon gift cards were randomly drawn and distributed based on the completion of the assessments.

\section{Data Analysis}

Analyses were conducted using $\mathrm{R}$ version 3.6.3. Descriptive statistics were calculated to summarize demographic and disease-related information and were compared in one-way ANOVAs or independent ttest. The level of statistical significance was set at $p<0.05$ for all computations. For the mediation analysis, the indirect, direct, and total effects of the total barriers to employment success (Barriers) on the differences between groups (Group) with quality of life (M1), anxiety (M2) and depression (M3) as the mediators, and employment hope sub-factors as the co-variates were examined to illustrate the use of 
methods of mediation analysis. The goal of this model was to investigate the total (Barriers) and direct effects (Group). It also investigated the indirect effect (IE) obtained from the product of coefficients. These influence measures were treated as both continuous and /or binary with the latter formed by dichotomization of the naturally continuous predictors in R syntax. Bootstrapping was applied to empirically estimate the sampling distribution of the indirect effect and generate a bootstrap confidence interval $(95 \% \mathrm{Cl})$ based on 10,000 bootstrap samples for bias corrected bootstrap Cls. Standard errors (SE) and confidence intervals $(\mathrm{Cl})$ were obtained, in the mediation analysis as recommended in Valeri \& Vanderweele ${ }^{25}$.

\section{Results}

\section{Descriptive Characteristics}

Of the NF1 Group, the average age was $43.6(\mathrm{SD}=12.5)$ with $66 \%(\mathrm{~N}=69)$ being female, as compared to the Matched Controls whose average was $30.1(\mathrm{SD}=10.2)$, and $56 \%(\mathrm{~N}=56)$ were female. A majority of each group (NF1: $65 \%$ [N=70]; Matched Control: $62 \%$ [N=67]) were actively employed, with only a small minority who were not employed (NF1: $11 \%$ [N=12]; Matched Controls: $16 \%$ [N=17]). In all cases of healthrelated issues, significant differences were noted between NF1 and Matched Controls. The remaining participant demographics and characteristics are displayed in Table 1. Significant differences between generalized anxiety, depression, employment barriers and hope across groups are shown in Table 2.

\section{Mediation Analysis}

A mediation analysis was performed to examine the indirect effects of generalized anxiety, depression and quality of life on the direct relationship of predictor variable (group) and outcome variable (barriers to employment). The levels of the Employment Hope Scale (EHS) as covariates used for this study included psychological empowerment (CV1), futuristic self-motivation (CV2), goal orientation (CV3), and utilization of skills and resources (CV4). The total effect (c) of group on total score was 17.73 (SE = 5.35, $t=3.31$, df $=207, p=0.001)$. The direct effect $\left(c^{\prime}\right)$ of group on total score removing mediator effects is $22.69(\mathrm{SE}=$ $5.23, t=4.33, d f=204, p<.001)$, the indirect effect $(a b)$ of group on total score through mediator effects is -4.96 . Also, the mean bootstrapped indirect effect is $-4.83(S D=4.06, \mathrm{Cl}=-12.72-3.24, \mathrm{p}<.001)$. The total effect of CV1 on the total score was -0.19 (SE $=0.42, t=-.046, \mathrm{df}=207, \mathrm{p}=0.65)$, total effect of CV2 on total score was $-0.96(\mathrm{SE}=0.58, t=-1.65, \mathrm{df}=207, \mathrm{p}=.10)$, total effect of CV3 on total score was $-0.60(\mathrm{SE}=0.63, t=-0.96, \mathrm{df}=207, \mathrm{p}=0.34)$, total effect of CV4 on total score was $2.53(\mathrm{SE}=0.79, t=$ $3.20, d f=207, p=0.0016)$. The direct effects for each level of the EHS includes psychological empowerment (CV1) -0.08 (SE $=0.37, t=-0.23, \mathrm{df}=204, \mathrm{p}=.82$ ), futuristic self-motivation $-0.72(\mathrm{SE}=$ $0.50, t=-1.43, \mathrm{df}=204, \mathrm{p}=.15)$, goal orientation $-0.50(\mathrm{SE}=0.55, t=-0.91, \mathrm{df}=204, \mathrm{p}=.36)$, and utilization of skills and resources $2.16(\mathrm{SE}=.69, t=3.14, \mathrm{df}=204, \mathrm{p}=.00)$.

\section{Generalized Anxiety (M1)}


The direct effect of Anxiety was $0.83(\mathrm{SE}=0.70, t=1.19, \mathrm{df}=204, \mathrm{p}=.24)$. The covariates used within the mediation analysis include psychological empowerment (CV1), futuristic self-motivation (CV2), goal orientation (CV3), and utilization of skills and resources (CV4). The indirect effect (ab) of CV1 on total score through mediator effects was $0.01(S D=0.07, C l=-0.14-0.17, p=.037)$. The indirect effect $(a b)$ of $\mathrm{CV} 2$ on total score through mediator effects was $0.00(\mathrm{SD}=0.11, \mathrm{Cl}=-0.25-0.23)$. The indirect effect (ab) of CV3 on total score through mediator effects was $-0.09(\mathrm{SD}=0.15, \mathrm{Cl}=-0.46-0.15, \mathrm{p}<.001)$. The indirect effect $(a b)$ of CV4 on total score through mediator effects was $0.02(S D=0.16, \mathrm{Cl}=-0.31-0.39)$.

\section{Depression (M2)}

The direct effect of Depression was 1.60 (SE $=0.65, t=2.47, \mathrm{df}=204, \mathrm{p}=.014$ ). The covariates used within the mediation analysis included psychological empowerment, futuristic self-motivation, goal orientation, and utilization of skills and resources. The indirect effect (ab) of CV1 on total score through mediator effects was $0.11(S D=0.14, \mathrm{Cl}=-0.12-0.46, p<0.001)$. The indirect effect $(a b)$ of $C V 2$ on total score through mediator effects was $-0.10(S D=0.19, C l=-0.54-0.25, p<0.001)$. The indirect effect $(a b)$ of $\mathrm{CV} 3$ on total score through mediator effects was $-0.28(\mathrm{SD}=0.25, \mathrm{Cl}=-0.87-0.09, \mathrm{p}<0.001)$. The indirect effect $(a b)$ of $\mathrm{CV} 4$ on total score through mediator effects was $0.02(S D=0.27, \mathrm{Cl}=-0.50-0.60)$.

\section{Quality of Life (M3)}

The direct effects of quality of life was $-2.32(\mathrm{SE}=0.44, t=-5.21, \mathrm{df}=204, \mathrm{p}=<.001)$. The covariates used within the mediation analysis include psychological empowerment, futuristic self-motivation, goal orientation, and utilization of skills and resources. The indirect effect (ab) of CV1 on total score through mediator effects was $-0.22(S D=0.14, C l=-0.53-0.01, p<0.001)$. The indirect effect $(a b)$ of $C V 2$ on total score through mediator effects was $-0.15(S D=0.16, C l=-0.50-0.17, p<0.001)$. The indirect effect (ab) of $\mathrm{CV} 3$ on total score through mediator effects was $0.28(\mathrm{SD}=0.18, \mathrm{Cl}=-0.04-0.67, \mathrm{p}<0.001)$. The indirect effect $(a b)$ of CV4 on total score through mediator effects was $0.36(S D=0.21, C l=0.02-0.83, p$ $<0.001)$.

\section{Discussion}

The current manuscript investigated the impact of depression, generalized anxiety, quality of life, and employment hope on to barriers to successful employment within individuals with NF1 compared to that of matched controls. Our results did confirm that work barriers fully mediate the relationship across individuals with NF1 to matched controls, and with quality of life, anxiety, and depression. Generalized anxiety, depression, and quality of life had both a direct and indirect effect, indicating a totally mediated relationship between these variables. The covariate employment hope had a significant direct effect, and only two sub-factors (self-motivation and utilization of skills and resources) demonstrated indirect relationships had significant effects. The findings indicate that the barriers of employment for individuals with NF1 to that of matched controls are critical underpinnings to that of quality of life, anxiety, and depression, thus emphasizing the importance of understanding of the impact of NF1 on those who experience the disease. To the authors' knowledge, the current study is the first to evaluate these 
constructs within the NF1 population, providing a clinical and vocational understanding which is missing within the current research.

The obtained results have several significant implications for individuals suffering with NF1 with respect to the impact of theoretical, future research, and clinical. From the theoretical perspective, when employment barriers (e.g. Personal and Financial, Emotional and Physical, Career Decision Making and Planning) are eliminated or reduced, improvement of quality of life can be maintained ${ }^{26}$. Maintaining a normalized sense of quality of life when suffering with a life-long disease or disability is critically important; thus, understanding the impact direct and indirect effects of mediating variables of employment barriers onto quality of life, depression and anxiety, supplements the existing research understanding of the of NF1 and how they experience the disease ${ }^{27-29}$.

From a research perspective, there were noted significant differences in depression between groups $(M=$ $19 \mathrm{NF} ; \mathrm{M}=13 \mathrm{MC}$ ) but generalized anxiety did not demonstrate a significant difference between groups $(M=14 N F ; M=11 M C)$. However, these differences did not impact the overall direct and indirect effects of the mediation analysis. The generalized anxiety findings did have stronger direct effects than depressive symptoms. The current findings add to the existing research that individuals with NF1 who have increased depression scores have poorer quality of life ${ }^{5,30}$. Multiple articles have demonstrated that individuals with NF1 suffer from generalized anxiety ${ }^{8,10}$. Yet the impact of employment barriers, a common sub-value in QoL measures, is particularly affected by generalized anxiety, as seen in the curent study. Indications of higher levels of anxiety can contribute to lower QoL 6, 8; however, more research is needed to evaluate how the barriers of employment can affect generalized anxiety. A recent metaanalysis concluded that QoL affects the well-being of the individual because of the impact onto physical, emotional, and cognitive functioning ${ }^{31}$. Looking at aggregate values, total barriers of employment were significantly higher for the control group than individuals with NF1, providing that while barriers such as physical, mental, social and societal pressures are constrained on individuals with NF1, the perception of work barriers may be perceived as secondary from a QoL perspective.

The way in which employment hope impacted the direct and indirect effects of the current study is compelling. Hong et al. ${ }^{22}$ discussed employment hope as a necessity in obtaining employment, as it increases the individual's opportunity to achieve employment. The immediate impact of employment hope has been found to influence sustainability of work related employment ${ }^{32}$. Yet, the indirect effects indicate that only self-motivation and utilization of skills can explain the observed relationship. This provides some initial understanding and explanation for the current findings, since the preexisting lifetime congenital condition may lead to a higher tolerance or wherewithal in individuals with NF1.

From a clinical perspective, the current findings echo previous reports that mental health was the consequence of and risk factor for unemployment, and that poorer mental health can be risk factor subsequent consequence of employment ${ }^{33}$. Overwhelmingly, and understandably, the physical manifestations of NF1 take precedent; however, other facets of QoL measures including active 
employment can provide a viable escape from the previous accompaniments, along with social integration and feelings of accomplishments. Given that individuals with NF1 have greater likelihood of having dyslexia and/or learning disabilities, individuals with NF1 may potentially require more external support ${ }^{1,34}$. Assistance programs, such as vocational rehabilitation, can customize services to meet the needs of individuals diagnosed with NF1, therefore potentially increasing labor force participation and decreasing psychological, physical, vocational, and social barriers related to employment ${ }^{16}$. Further research is needed to understand the impact of work barriers within NF1 individuals. Maintaining normalcy for individuals with NF1 is an arduous task given the multiple and complex medical, psychological, emotional and occupational deficits which can accompany the disease.

The current study is not without limitations. Initially, the current study was a cross-sectional design with an under-powered sample of individuals with NF1. Although an inference or causal relationship cannot be found using cross-sectional methodology, the current study can provide future directions for researchers on the impact of anxiety and depression on work barriers. Relative to other large-scale research studies with NF1 adults ${ }^{5,35}$ the current study has a modest representation of individuals with NF1. Given the rarity of the disease, a well-powered study is difficult to attain. Additional research should attempt to increase the sample size, thus allowing for a greater external validity of the results. Lastly, typical QoL measures can include questions regarding employment. Yet, parsing out the barriers of employment and employment hope (QoL sub-factors) within the NF1 population has not been completed. Future research should investigate the underlying features of the current study (e.g., barriers of employment, employment hope, quality of life, depression and generalized anxiety) in a more clinical capacity through a more systematic process. By including other variables that can affect quality of life functioning will allow for clearer causation of differentiation. Additionally, the impact of across NF1, NF2 and Schwannomatosis should be considered, given each presentation of the corresponding diseases are inherently different.

\section{Conclusions}

The current article is the first to demonstrate that quality of life can directly be affected by barriers of employment within the NF1 population. Results extend existing research by providing insight on the impact of quality of life on employment. Poorer mental health observed amongst people with a genetic disease can impact both barriers of employment and quality of life. Through better understanding the factors that negatively impact barriers to employment, assistance programs can tailor services for individuals with NF1, potentially increasing labor force participation and QoL.

\section{Declarations}

\section{Ethics approval and consent to participate}

The current study was approved by the Yale University Human Subjects Committee (2000026514).

\section{Consent for publication}


Not applicable

\section{Availability of data and materials}

The data that support the findings of this study are available on request from the corresponding author. The data are not publicly available due to privacy or ethical restrictions.

\section{Competing Interests}

The authors declare that they have no competing interests

\section{Funding}

This work was supported by the U.S. Army Medical Research Materiel Command endorsed by the U.S. Army, through the Congressionally Directed Medical Research Programs' Neurofibromatosis Research Program under Award No. W81XWH-19-1-0618.

\section{Author Contributions}

FB: Designed the study, helped analyze the findings, maintained the IRB, and contributed to writing the manuscript

MS: Helped analyze the findings, wrote up the results section, provided edited revisions

EP: Completed the statistical analysis, provided mentorship to MS in writing up the results, provided edited revisions

SM: Mentored the first author on research design, wrote clinicial implications, and provided edited revisions

$\mathrm{KL}$ : Maintained the data, constructed the endnote file, helped construct the introduction, provided edited revisions

AG: Mentored the first author, provided medical formations and clinical importance of the findings, provided edited revisions.

\section{Acknowledgements}

We would like to thank Karen Peluso, Director of NF Northeast and Kim Bischoff, Director of NF Network for their help and commitment. There are no conflicts of interest to report across all authors on file.

\section{References}

1. Anderson JL, Gutmann DH. Neurofibromatosis type 1. Handb Clin Neurol 2015; 132:75-86. 
2. Kodra Y, Giustini S, Divona L, Porciello R, Calvieri S, Wolkenstein P, et al. Health-related quality of life in patients with neurofibromatosis type 1. A survey of 129 Italian patients. Dermatology 2009; 218:215-20.

3. Radtke HB, Sebold CD, Allison C, Haidle JL, Schneider G. Neurofibromatosis type 1 in genetic counseling practice: recommendations of the National Society of Genetic Counselors. J Genet Couns 2007; 16:387-407.

4. Tonsgard JH. Clinical manifestations and management of neurofibromatosis type 1. Semin Pediatr Neurol 2006; 13:2-7.

5. Cohen JS, Levy HP, Sloan J, Dariotis J, Biesecker BB. Depression among adults with neurofibromatosis type 1: prevalence and impact on quality of life. Clin Genet 2015; 88:425-30.

6. Ormel J, VonKorff M, Ustun TB, Pini S, Korten A, Oldehinkel T. Common Mental Disorders and Disability Across Cultures: Results From the WHO Collaborative Study on Psychological Problems in General Health Care. JAMA 1994; 272:1741-8.

7. Plaisier I, de Graaf R, de Bruijn J, Smit J, van Dyck R, Beekman A, et al. Depressive and anxiety disorders on-the-job: the importance of job characteristics for good work functioning in persons with depressive and anxiety disorders. Psychiatry Res 2012; 200:382-8.

8. Ferner RE, Thomas M, Mercer G, Williams V, Leschziner GD, Afridi SK, et al. Evaluation of quality of life in adults with neurofibromatosis 1 (NF1) using the Impact of NF1 on Quality Of Life (INF1-QOL) questionnaire. Health Qual Life Outcomes 2017; 15:34-.

9. Ferner RE. Psychological Impact of the Neurofibromatoses. Neurofibromatoses in Clinical Practice. London: Springer London, 2011:129-40.

10. Pasini A, Lo-Castro A, Di Carlo L, Pitzianti M, Siracusano M, Rosa C, et al. Detecting anxiety symptoms in children and youths with neurofibromatosis type I. Am J Med Genet B Neuropsychiatr Genet 2012; 159B:869-73.

11. Page PZ, Page GP, Ecosse E, Korf BR, Leplege A, Wolkenstein P. Impact of neurofibromatosis 1 on Quality of Life: a cross-sectional study of 176 American cases. Am J Med Genet A 2006; 140:1893-8.

12. Wolkenstein P, Zeller J, Revuz J, Ecosse E, Leplege A. Quality-of-life impairment in neurofibromatosis type 1: a cross-sectional study of 128 cases. Arch Dermatol 2001; 137:1421-5.

13. Vranceanu AM, Merker VL, Park E, Plotkin SR. Quality of life among adult patients with neurofibromatosis 1, neurofibromatosis 2 and schwannomatosis: a systematic review of the literature. J Neurooncol 2013; 114:257-62.

14. Ruchlin HS, Morris JN. Impact of work on the quality of life of community-residing young elderly. Am J Public Health 1991; 81:498-500.

15. Zaninotto P, Falaschetti E, Sacker A. Age trajectories of quality of life among older adults: results from the English Longitudinal Study of Ageing. Qual Life Res 2009; 18:1301-9.

16. McCabe M, Sprong ME, Dallas B, Mui N, Upton T. Program effectiveness of vocational evaluation as quantified by the Career Planning Scale. VEWAA 2013; 40:12-22. 
17. Rocha C, Crowell JH, McCarter AK. The Effects of Prolonged Job Insecurity on the Psychological Well-Being of Workers. Journal of Sociology and Social Welfare 2006; 33:9-28.

18. Krueger AB, Mueller A, Davis SJ, Sahin A. Job search, emotional well-being, and job finding in a period of mass unemployment: Evidence from high frequency longitudinal data. Brookings apers on Economic Activity, 2011.

19. Wolters PL, Martin S, Merker VL, Gardner KL, Hingtgen CM, Tonsgard JH, et al. Patient-reported outcomes in neurofibromatosis and schwannomatosis clinical trials. Neurology 2013; 81:S6-14.

20. Spitzer RL, Kroenke K, Williams JB, Lowe B. A brief measure for assessing generalized anxiety disorder: the GAD-7. Arch Intern Med 2006; 166:1092-7.

21. Kroenke K, Spitzer RL, Williams JB. The PHQ-9: validity of a brief depression severity measure. J Gen Intern Med 2001; 16:606-13.

22. Hong PYP, Choi S, Polanin JR. A Multisample Confirmatory Factor Analysis of the Short Employment Hope Scale (EHS-14). Journal of Social Service Research 2014; 40:339-52.

23. Liptak JJ. Barriers to Employment Success: Identifying barriers to getting and keeping a job. Aurora, ON: Jist Publishing, Inc, 2018.

24. Stewart AL, Hays RD, Ware JE, Jr. The MOS short-form general health survey. Reliability and validity in a patient population. Med Care 1988; 26:724-35.

25. Valeri L, Vanderweele TJ. Mediation analysis allowing for exposure-mediator interactions and causal interpretation: theoretical assumptions and implementation with SAS and SPSS macros. Psychol Methods 2013; 18:137-50.

26. Rubin SE, Roessler RT, Rumrill Jr. PD. Foundations of the vocational rehabilitation process Austin, TX: Pro-Ed In, 2016.

27. Doser K, Andersen EW, Kenborg L, Dalton SO, Jepsen JRM, Krøyer A, et al. Clinical characteristics and quality of life, depression, and anxiety in adults with neurofibromatosis type 1: A nationwide study. American Journal of Medical Genetics Part A 2020; 182:1704-15.

28. Ferner RE, Gutmann DH. Neurofibromatosis type 1 (NF1): diagnosis and management. Handbook of clinical neurology: Elsevier, 2013:939-55.

29. Wolters PL, Martin S, Merker VL, Tonsgard JH, Solomon SE, Baldwin A, et al. Patient-reported outcomes of pain and physical functioning in neurofibromatosis clinical trials. Neurology 2016; 87:S4-S12.

30. Bicudo NP, de Menezes Neto BF, da Silva de Avo LR, Germano CM, Melo DG. Quality of Life in Adults with Neurofibromatosis 1 in Brazil. J Genet Couns 2016; 25:1063-74.

31. Sanagoo A, Jouybari L, Koohi F, Sayehmiri F. Evaluation of QoL in neurofibromatosis patients: a systematic review and meta-analysis study. BMC Neurology 2019; 19:123.

32. Hong PYP, Sheriff VA, Naeger SR. A bottom-up definition of self-sufficiency: Voices from low-income jobseekers. Qualitative Social Work 2009; 8:357-76. 
33. Olesen SC, Butterworth P, Leach LS, Kelaher M, Pirkis J. Mental health affects future employment as job loss affects mental health: findings from a longitudinal population study. BMC Psychiatry 2013; 13:144.

34. Hyman SL, Shores A, North KN. The nature and frequency of cognitive deficits in children with neurofibromatosis type 1 . Neurology 2005; 65:1037-44.

35. Varni JW, Nutakki K, Swigonski NL. Speech difficulties and patient health communication mediating effects on worry and health-related quality of life in children, adolescents, and young adults with Neurofibromatosis Type 1. Am J Med Genet A 2019; 179:1476-82.

\section{Tables}

Table 1. Demographics and Medical Information across Groups 


\begin{tabular}{|c|c|c|c|}
\hline & NF Group $(\mathrm{N}=105)$ & Matched Control $(\mathrm{N}=108)$ & P-Value \\
\hline Age & $43.6(12.5)$ & $30.1(10.2)$ & \\
\hline Gender Identification; N (\%) & & & 0.38 \\
\hline Male & $35(33 \%)$ & $45(42 \%)$ & \\
\hline Female & $69(66 \%)$ & $60(56 \%)$ & \\
\hline Transgender & 0 & $2(2 \%)$ & \\
\hline Other & $1(1 \%)$ & $2(2 \%)$ & \\
\hline Marital Status; N (\%) & & & 0.28 \\
\hline Single & $46(43 \%)$ & $55(50 \%)$ & \\
\hline Married & $43(41 \%)$ & $42(39 \%)$ & \\
\hline Divorced & $9(9 \%)$ & $6(6 \%)$ & \\
\hline Separated & $2(2 \%)$ & $2(2 \%)$ & \\
\hline Widowed & $3(3 \%)$ & 0 & \\
\hline Other & $2(2 \%)$ & $3(3 \%)$ & \\
\hline Highest Education & & & 0.009 \\
\hline High school/GED & $21(20 \%)$ & $37(34 \%)$ & \\
\hline Technical Degree & $13(12 \%)$ & $7(6 \%)$ & \\
\hline Some of College & $9(9 \%)$ & $8(7 \%)$ & \\
\hline Bachelor's Degree & $12(11 \%)$ & $13(12 \%)$ & \\
\hline Advanced Degree & $12(11 \%)$ & $7(6 \%)$ & \\
\hline Work Status & & & .84 \\
\hline Employed & $70(65 \%)$ & $67(62 \%)$ & \\
\hline Student & $5(5 \%)$ & $13(12 \%)$ & \\
\hline Retired & $5(5 \%)$ & $3(3 \%)$ & \\
\hline Worker's Compensation & $1(1 \%)$ & $1(1 \%)$ & \\
\hline Receive SSD/SSI & $12(11 \%)$ & $6(6 \%)$ & \\
\hline Unemployed & $12(11 \%)$ & $17(16 \%)$ & \\
\hline \multicolumn{4}{|l|}{ Health Related IIInesses; Yes } \\
\hline Responses (\%) & & & \\
\hline
\end{tabular}




\begin{tabular}{|lllr|}
\hline Respiratory/Breathing/Pulmonary & $30(29 \%)$ & $14(13 \%)$ & 0.005 \\
\hline Gastrointestinal & $20(19 \%)$ & $11(10 \%)$ & 0.067 \\
\hline Urinary/Genital & $49(47 \%)$ & $13(12 \%)$ & $<.001$ \\
\hline Musculoskeletal & $29(28 \%)$ & $10(9 \%)$ & $<.001$ \\
\hline Rheumatologic/Immunologic & $41(40 \%)$ & $13(12 \%)$ & $<.001$ \\
\hline Neurological & $26(25 \%)$ & $8(7 \%)$ & $<.001$ \\
\hline
\end{tabular}

Table 2. Results of Anxiety, Depression, QoL, Total Barriers of Employment and Employment Hope between groups (NF1 vs. Matched Control)

\begin{tabular}{|c|c|c|c|c|c|c|c|}
\hline & \multicolumn{2}{|l|}{ NF1 } & \multicolumn{2}{|l|}{ MC } & \multirow[t]{2}{*}{$t$} & \multirow[t]{2}{*}{$d f$} & \multirow[t]{2}{*}{$p$} \\
\hline & $M$ & SD & $M$ & SD & & & \\
\hline Generalized Anxiety & 14.4 & 5.91 & 11.37 & 4.73 & 4.14 & 211 & $<.001$ \\
\hline Quality of Life & 32.1 & 2.8 & 29 & 6.5 & 4.37 & 211 & $<.001$ \\
\hline Depression & 18.7 & 6.87 & 13.18 & 4.98 & 6.74 & 211 & $<.001$ \\
\hline Total Barriers to Employment & 24.1 & 5.4 & 19.6 & 7.2 & 5.02 & 211 & $<.001$ \\
\hline $\begin{array}{l}\text { Employment Hope - Psychological } \\
\text { Flexibility }\end{array}$ & 29.6 & 9.56 & 26.22 & 10.01 & 2.52 & 211 & 0.013 \\
\hline Employment Hope - Self-Motivation & 12.47 & 6.4 & 12.48 & 5.1 & -0.19 & 211 & NS \\
\hline Employment Hope - Goal Orientation & 17.24 & 9.1 & 18.8 & 7.5 & -1.34 & 211 & NS \\
\hline Employment Hope - Utilization of Skills & 29.6 & 9.56 & 26.22 & 10.01 & 2.52 & 211 & 0.013 \\
\hline
\end{tabular}

Note. $\mathrm{M}=$ =Mean; $\mathrm{SD}=$ Standard Deviation; NF1 = Neurofibromatosis Type 1; MC= Matched Controls; $\mathrm{df}=$ Degrees of Freedom, NS= not significant.

\section{Figures}




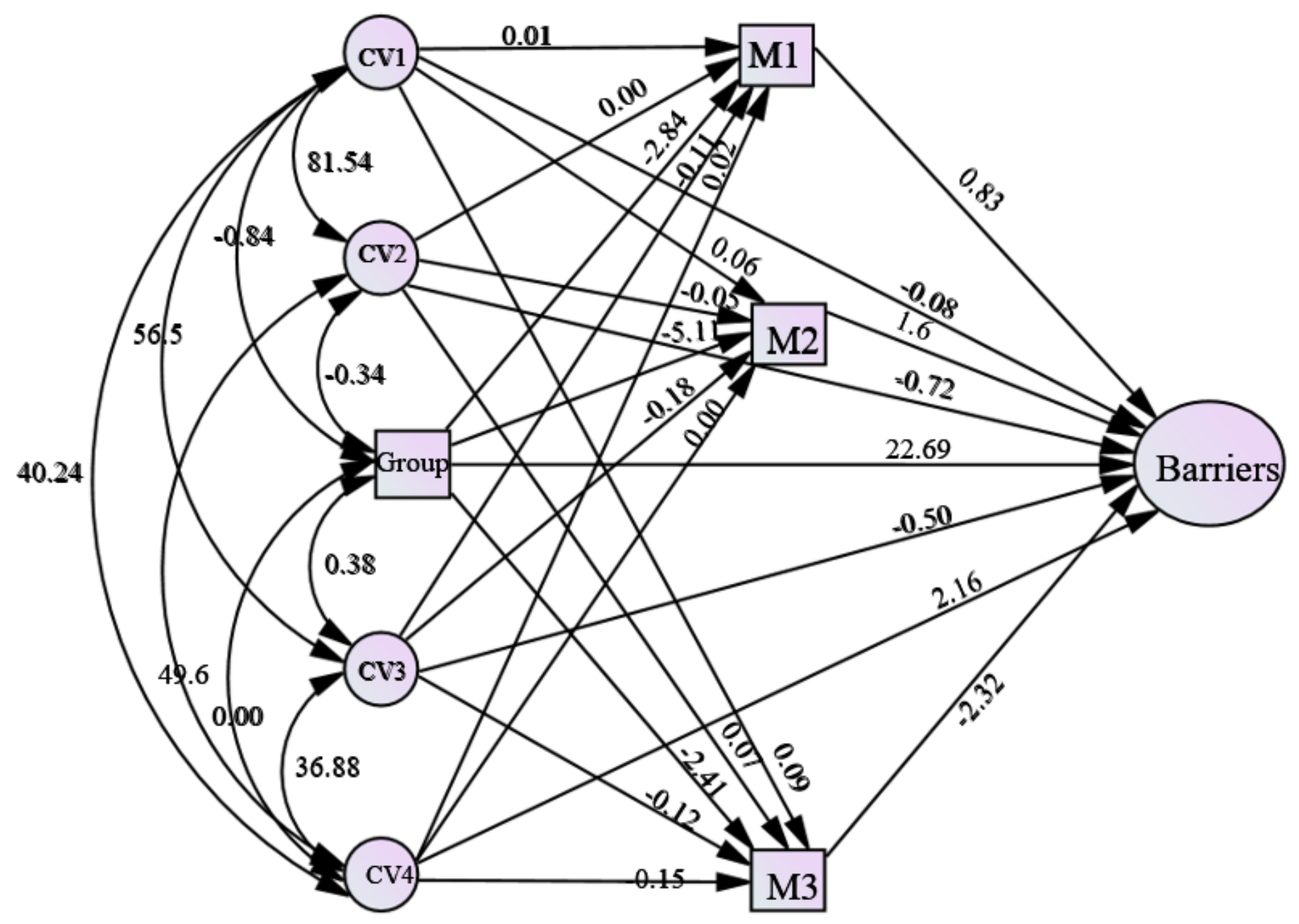

Figure 1

Mediation Analysis of Work Barriers Across NF1 and Matched Controls. Note: Barriers= Total Score of Barriers to employment success inventory; Group= Grouping variable (NF1 or Matched Controls); M1= Generalized Anxiety Total Score; M2= Patient Health Questionnaire Total Score; M3= Short Form-12 Total Score; CV1 = Employment Hope psychological empowerment subfactor; CV2= Employment Hope futuristic self-motivation subfactor; CV3= Employment Hope goal orientation subfactor: CV4= Employment Hope utilization of skills and resources subfactor. 